\title{
E-Commerce During COVID-19 Lockdown 2020: Challenges and Opportunities For Consumer Rights In Uganda
}

\author{
Candia Emmanuel*
}

\begin{abstract}
Both the government of Uganda and Jumia Uganda effectively used the Covid-19 pandemic lockdown measures of 2020 to promote e-commerce services. This study adopted a qualitative research methodology. The researcher elicited random responses over a Facebook page regarding consumer experience using Jumia Uganda during the lockdown. The study engaged a population size of about 5,000 persons and a target sample size of 100 participants on Facebook of which 50 persons responded. The study found that $66 \%$ of the respondents had a bad experience using the Jumia Uganda platform compared to $34 \%$ who had a good experience. Although e-commerce was widely promoted and used, e-commerce service consumers had a bitter-sweet cocktail of experiences. Critical challenges of the business include: poor quality and counterfeit products, delivery challenges, high cost of shipping and pricing of products, cancellation, return, refund, repurchase challenges, and lack of an effective dispute resolution mechanism. The study recommends the improvement of the delivery mechanisms, quality verification, and certification process, and the creation of an online dispute resolution mechanism to boost consumer confidence and interest in e-commerce.
\end{abstract}

Key words: E-commerce/ Covid-19/ Consumer Rights/ Trade/ Online Trade/ Online Dispute Resolution.

DOI: $10.7176 / \mathrm{JMCR} / 82-06$

Publication date:November $30^{\text {th }} 2021$

\section{Introduction:}

Globally, e-commerce ${ }^{1}$ continues to leap in growth from about $\$ 9.09$ trillion since 2019 at a projected rate of $14.7 \%$ through 2020 to 2027 driven by increasing internet penetration, mobile technologies, technology awareness,

\footnotetext{
*LLB (Hons) (UCU), Dip. LP (LDC), LLM (UCU), Advocate, Commissioner of Oaths and Lecturer in Law, a founding Managing Partner at M/s Candia Advocates and Legal Consultants. He has earlier researched on the adequacy of the Electronic Transactions Act in Governing E-Commerce in Uganda. Available at http://dx.doi.org/10.2139/ssrn.3325932

${ }^{1}$ E-commerce is defined as 'the sale or purchase of goods or services, whether between businesses, households, individuals, governments, and other public or private organizations, conducted over computer-mediated networks. The consumer orders the goods and services over those networks, but the payment and the ultimate delivery of the good or service may be conducted on or off-line, OECD Expert Group on Defining and Measuring E-Commerce, April 2000, see https://stats.oecd.org/glossary/detail.asp?ID=758 (accessed on the 30th June 2021);
}

In -T. Garín-Muñoz, T. Pérez-Amaral, Factores determinantes del comercio electrónico en España. Boletín económico de ICE, Informacion Comercial Espanola, 3016 (2011), pp. 51-65-e-commerce is defined to mean "the use of the internet to buy, sell or support products and services, not only as an economic exchange, it also includes the exchange of information and post-sale support"

S.2 of the Electronic Transactions Act (hereinafter abridged as 'ETA') defines the term to mean 'the exchange of information or data, the sale or purchase of goods or services, between businesses, households, individuals, governments, and other public or private organizations, conducted over computer-mediated networks.' 
and big data. ${ }^{2}$ Africa's over $\$ 180$ billion internet economy leans on e-commerce and fintech. ${ }^{4}{ }^{5}$ E-commerce is continuing to be driven by the payment landscape, rise in mobile tech, and mobile money tech adoption. ${ }^{6}$ In Uganda, the widespread use of mobile money and mobile phone usage explains the rapid growth of e-commerce. ${ }^{7}$

A fair share of global trade is now handled through e-commerce platforms giving extensive and almost unlimited access to goods and services across the globe. ${ }^{8}$ Uganda has put in place an enabling policy and legal framework nurtured by proactive government initiatives for the young and innovative population, which has grown ecommerce into a great contributor to the national GDP rates.

Several e-commerce platforms have opened up in Uganda in recent years, and these have become the go-to place for both sellers and buyers of all manner of products. They have provided employment opportunities for Uganda's young and entrepreneurial population. ${ }^{9}$ In the wake of COVID- $19^{10}$, advocates of e-commerce and e-payment systems ${ }^{11}$, FinTech, crypto-currency ${ }^{12}$ enthusiasts pushed forward the agenda and view of the world going digital. The Government and Mobile Telecom Service providers in Uganda took positive steps to ensure the population is safe by removing charges on transfer or withdrawal of mobile money in facilitating business and other transactions during the lockdown.

The President of Uganda in one of the nation addresses responding to the challenge of COVID-19 ${ }^{13}$ advised people to stay at home, purchase goods electronically using their phones or computers, and wait for the delivery at their homes. The government adopted the stay-home measure as the most effective way of addressing the risk of

\footnotetext{
2 Big data refers to large sets of complex data, both structured and unstructured which traditional processing techniques and or algorithms are unable to operate on. It aims to reveal hidden patterns and has led to an evolution from a model-driven science paradigm into a data-driven science paradigm.
}

See Kevin Taylor-Sakyi, Big Data: Understanding Big Data, Engineering and Applied Science, Aston University, Birmingham, England, 2016, Available at: (PDF) Big Data: Understanding Big Data (researchgate.net), [accessed August 8, 2021]

${ }^{3}$ E-commerce Market Size, Share \& Trends Analysis Report by Model Type (B2B, B2C), By Region (North America, Europe, APAC, Latin America, Middle East \& Africa), And Segment Forecasts, 2020-2027, Published May 2020, See: E-commerce Market Share, Growth \& Trends Report, 2020-2027 (grandviewresearch.com) accessed on the 30th June 2021

${ }^{4}$ Defined as 'computer programs and other technology used to support or enable banking and financial services. See: fintech definition - Bing visited on June 30, 2021. e-Conomy-Africa-2020-Exe-Summary.pdf (ifc.org) visited on 30th June 2021

${ }^{5}$ Ibid.

${ }^{6}$ Ibid

${ }^{7}$ See Uganda - eCommerce (trade.gov) visited June 30, 2021

${ }^{8}$ Fernando Fernández-Bonilla, Covadonga Gijón, Bárbara De la Vega, E-commerce in Spain: Determining factors and the importance of the e-trust, Telecommunications Policy, 2021, 102280, ISSN 0308-5961, https://doi.org/10.1016/j.telpol.2021.102280. (https://www.sciencedirect.com/science/article/pii/S0308596121001841),

${ }^{9}$ Ibid

${ }^{10}$ Coronavirus disease (COVID-19) is an infectious disease caused by a newly discovered coronavirus. Most people infected with the COVID-19 virus will experience mild to moderate respiratory illness and recover without the need for special treatment. Older people and others with underlying medical problems like cardiovascular disease, diabetes, chronic respiratory disease, and cancer are more likely to develop serious illnesses. See Coronavirus (who.int) visited on June 26, 2021

${ }^{11}$ S.1 of the National Payment Systems Act, 2020 defines "payment system" to mean a system used to effect a transaction through the transfer of monetary value and includes the institutions, payment instruments, person, rules, procedures, standards, and technologies that make such a transfer possible;

12 The Oxford Dictionary defines Cryptocurrency as 'a digital currency in which transactions get verified and records maintained by a decentralized system using cryptography, rather than by a centralized authority. See:

${ }^{13}$ Presidential Address on the 31st of March 2020 
infections and the safest trading method. ${ }^{14}$ Research, though not directly linked to pandemics, shows that ecommerce has a more positive impact on the economy during times of crisis compared to other forms of trade and contributes to eliminating some negative effects of crisis. ${ }^{15}$ Another scientific research conducted in Japan reveals that with increase in stay-at-home duration there were decreases the opportunity to shop at retail stores and a significant usage of e-commerce. ${ }^{16} 17$

Jumia Uganda, ${ }^{18}$ launched before Covid-19 became a major go-to e-commerce platform that took advantage of the prospects offered by the COVID-19 pandemic and offered its services to the Ugandan population. Owing to the lockdown measures, they offered one of the most convenient and safe mechanisms for keeping Ugandans safe yet connected to the market electronically.

\section{Background:}

A central factor to any business transaction is the consumer. A consumer is a person who buys goods or services for personal, family, or household use, with no intention of resale. A consumer also means 'a natural person who uses products for personal rather than business purposes. ${ }^{\prime 19}$ The Sale of Goods and Supply of Services Act (hereinafter abridged as 'SGSSA') defines a consumer as a person who purchases goods and services for final use or ownership rather than for resale or use in production. ${ }^{20}$

Over time, consumer protection laws have developed to guarantee fair trade and credit practices and protect consumers against faulty and dangerous goods. ${ }^{21}$

Uganda has no Consumer rights specific law but an ecosystem of a robust policy and legal framework governing business and trade broadly and e-commerce as part of the component. ${ }^{22}$ The policy and legal frameworks regulate

14 UNCTAD, Ugandan e-commerce platforms power recovery from COVID-19 crisis, 28 July 2020, also found

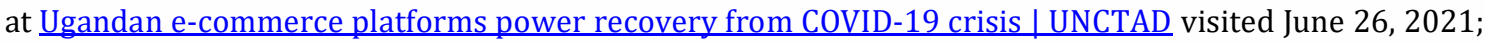
also see UNDP Uganda, COVID-19: UNDP, JUMIA Uganda partner to link market vendors with consumers online, May 11, 2020, found at COVID-19: UNDP, JUMIA Uganda partner to link market vendors with consumers online | UNDP in Uganda visited June 26, 2021

${ }^{15}$ Mesut Savrul, Cüneyt Kılıç, E-Commerce as an Alternative Strategy in Recovery from The Recession, $7^{\text {th }}$ International Strategic Management Conference, Elsevier Ltd, Procedia Social and Behavioral Sciences, Vol.24, 2011, pg. 247-259 doi: 10.1016/j.sbspro.2011.09.055 (accessed on $28^{\text {th }}$ October 2021)

${ }^{16}$ Tomoya Kawasaki, Hisayuki Wakashima, Ryuichi Shibasaki, The use of e-commerce and the COVID-19 outbreak: A panel data analysis in Japan, Transport Policy, Volume 115, 2022, Pages 88-100, ISSN 0967070X,https://doi.org/10.1016/j.tranpol.2021.10.023. (https://www.sciencedirect.com/science/article/pii/S0967070X2100305X), [Accessed on 28 ${ }^{\text {th }}$ October 2021]

${ }^{17}$ A. Bhatti, H. Akram, H.M. Basit, A.U. Khan, S. Mahwish, R. Naqvi, et al. E-commerce trends during COVID-19 Pandemic, International Journal of Future Generation Communication and Networking, 13 (2) (2020), pp. 1449-1452, ISSN: 2233-7857 IJFGCN,

${ }^{18}$ Jumia Uganda is a leading pan-African e-commerce platform present across 14 countries in Africa. They believe that technology has the potential to transform everyday life in Africa for the better. Jumia helps consumers access millions of goods and services conveniently and at the best prices while opening up a new way for sellers to reach consumers and grow their businesses. See About Jumia Group | Get to know more about us | Jumia Group visited June 26, 2021

${ }^{19}$ Black's Law Dictionary, $8^{\text {th }}$ Edition, 2004, pg. 951

${ }^{20}$ S. 1 of the SGSSA, 2018

${ }^{21}$ Supra note 16.

${ }^{22}$ ETA; The Electronic Transactions Regulations, 2013; the Computer Misuse Act, 2011; Electronic Signatures Act, 2011; The Electronic Signatures Regulations 2013 -SI 43 of 2013; the SGSSA, 2018; the Data Protection and Privacy Act, 2019; Draft Data Protection and Privacy Regulations 2019; The NITA-U (Certification of IT Providers and Services) Regulations, 2016 SI No. 69 of 2016; NITA-U (E-Government Regulations) 2015 -SI No. 27 of 2015 and more recently, the National Payment Systems Act, 2020 are among some of the laws governing e-commerce in Uganda. 
business transactions by defining the nature of acceptable transactions, rights, and duties of parties. Some of the aspects regulated include quality of goods, prohibited or restricted imports.

Purchasing goods or services through e-commerce or digital platforms is a consumer protection issue emphasized in the legal and policy framework. Various service providers are engaged in trading using different electronic or digital systems. Some do not fully comply with the legal requirements, while others attempt to.

The National Competition and Consumer Protection Policy, 2014 aligned to the National Vision 2040, the National Development Plan III (2020-2024), the National Trade Policy, and other sectoral policies sought for a need to protect consumers in Uganda. The National Competition and Consumer Protection Policy envisages an environment of fair competition that spurs innovation, productivity, increases the growth of SMEs, increases incomes, wealth creation, and sustainable development as critical national objectives. ${ }^{23}$ The policy underscores consumer welfare and guards them against exploitation. Despite the robust and elaborate legal framework, many consumers continue to face practical challenges. The challenges of the lack of mechanisms for dispute resolution, quality assurance, price monitoring, and delivery of products create a dampened space for effective growth of ecommerce.

By carrying out an empirical research on the commercial practice, this paper extracts previously concealed frustrations and appreciations to refocus a deeper analysis of consumer rights. Contextualized within the COVID19 pandemic reduction measures of a lockdown and premised on the elaborate legal framework, it digs into the practical experiences of consumers to unearth the good, bad and ugly experiences. The paper proffers a legal analysis laced with the practice and makes some workable policy proposals.

\section{Methodology:}

The research adopted a qualitative method. The sample size was determined by the frequency of the participants using social media in a particular time of Covid-19 first phase lockdown for a period of one week from the $20^{\text {th }}$ of May to the $26^{\text {th }}$ of May 2020. The participants or respondents considered are the persons who randomly responded to the research question administered to the researcher's friends on a Facebook page. ${ }^{24}$

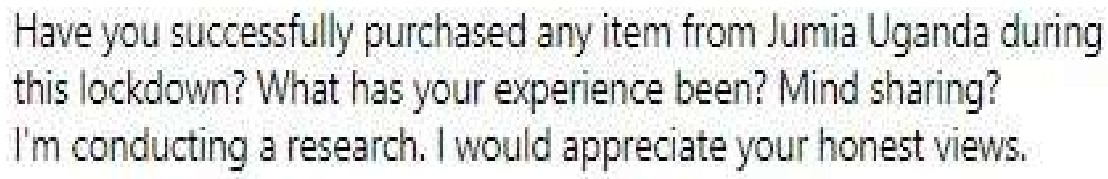

Question administered on the Facebook page on May 20, 2020

The methodology provided a safe and effective way to reach out to a population size of about 5000 people. This population size was ascertained from the number of Facebook friends the researcher had at the time.

A target sample size of 100 respondents was expected to respond. This sample size was chosen to ease the monitoring on the frequency of internet and social media users and also the short period of time the researcher had to carry out the research.

The choice of the sample size was further informed by challenges in accessing internet for many Ugandans who experienced prohibitive data costs caused by Over-the-Top Tax (OTT) imposed prior to the lockdown. Another consideration was the history of average possible responses on any issue raised by the researcher on his Facebook page. The third consideration was the continuous encouragement of the locked up population to adopt digital mechanisms to continue trading activities.

23

${ }^{24}$ This particular methodology was considered because the respondents could only be accessible through the social media. The period for the lockdown was unprecedented to the social life of most Ugandans. The period also saw changed communication from physical meetings to online platforms. This particular week was when the President of Uganda was expected to ease the lockdown measures. Extending the period of the research would mean the respondents sharing experiences where they had other options for accessing the market physically. 
These provided an effective and less costly way of reaching out to many respondents with rich and practical experiences. The responses elicited from the respondents formed the basis of the findings in this paper.

Ethical Considerations: As all the respondents freely shared their minds on the subject, their identities and personal information has not been revealed in this this report. Further, the responses of the respondents gave were deleted/specifically blocked from being openly accessed to protect the identities of the respondents.

The findings are presented and analyzed based on thematic areas that emerged from the respondents.

Findings:

50 Facebook friends responded to the question. There were 154 comments in total and 52 likes. Of the 50 respondents, 7 respondents representing $14 \%$ of the total respondents didn't answer the question directly but encouraged others to share views or made references. All such persons so encouraged to participate or referred didn't respond to the question. 2 respondents made other observations not directly related to the question. The comments were therefore not considered in this analysis. The findings and analysis set in this paper based on the responses of 43 respondents, representing $86 \%$ of the total respondents.

$5 \%$ of the respondents shared experiences outside the period under research extending up to two years back. These experiences were adopted and considered relevant to the study as they raised pertinent concerns.

A graphical representation of the data collected related to male and female shared experiences of purchases on Jumia Uganda by May 26, 2020 is below.

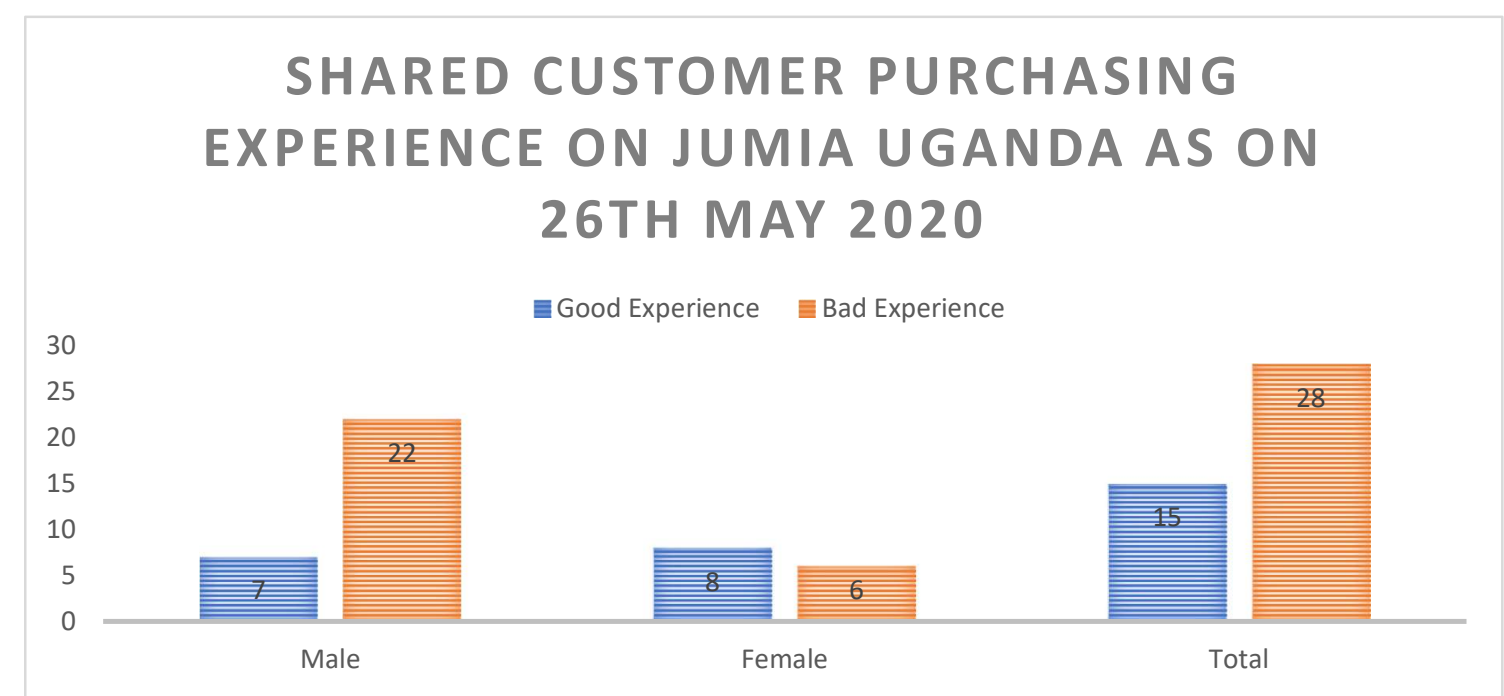

The use of the Jumia Uganda e-commerce platform has left a bitter-sweet taste in the mouths of consumers. For some consumers, there were great experiences with all the customer expectations met or superseded, while others were left cursing and disparaging the platform. 
$67 \%$ of the respondents were male, $33 \%$ of the respondents were female. $34 \%$ of the total respondents reported having had a good experience ${ }^{25}$ using the Jumia Uganda platform, while $66 \%$ reported having had bad experiences. $^{26}$

$24 \%$ of the males reported having had a good experience, while $76 \%$ of the male respondents reported having had a bad experience purchasing on Jumia. $57 \%$ of the female respondents had experienced a good experience purchasing on Jumia Uganda compared to $43 \%$ who reported having bad experiences.

In analyzing the consumer experiences, macro-level concerns are excluded. Some of these concerns include infrastructure, internet access, connectivity, cost of data, and lack of electricity.

On average, more females reported having had a better experience purchasing on the Jumia Uganda platform compared to their male counterparts. Although, more males have engaged more actively on the platform than females.

\section{Nature of products:}

The customers purchased assorted goods ranging from food to electronics, appliances, and even kitchenware. Others range from personal effects to lifestyle and entertainment gadgets. Below is a table of the types of goods purchased by the various respondents.

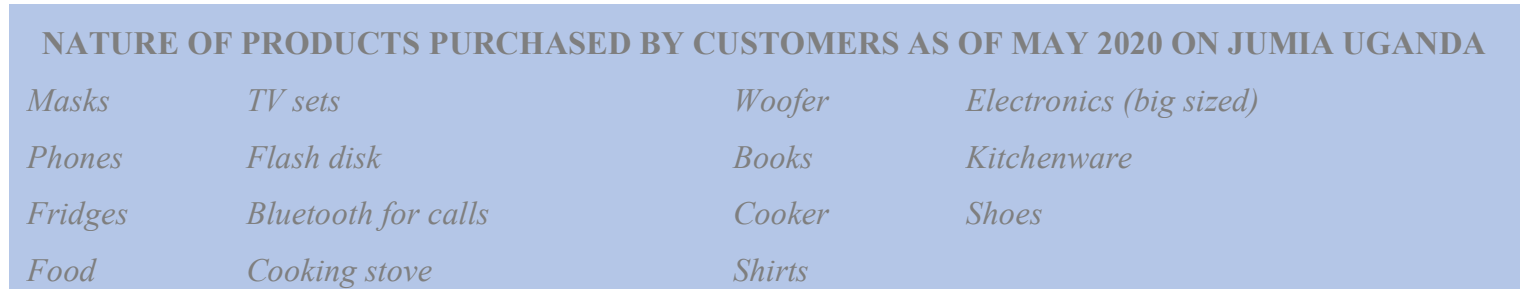

Table showing the nature of products purchased by the various respondent.

Delivery:

Delivery is the voluntary transfer of possession from one person to another. It includes an appropriation of goods to the contract that results in the property in the goods being transferred to the buyer. ${ }^{27}$ Black's Law Dictionary ${ }^{28}$ defines delivery as 'the formal act of transferring something, such as a deed; the giving or yielding possession or control of something to another.' The terms and conditions of the contract determine the taking possession of the goods. These may be express or implied terms within every particular contract of sale. ${ }^{29}$ Where there is no express or implied contract about where to deliver the goods, the seller's place of business or their residence as the case

${ }^{25}$ In the context of this study, a 'good experience' means having had no problems with making the order online, at a relatively reasonable price, and the goods were promptly delivered and as expected. It further means having experienced good customer care, effective communication, the exact product ordered for is delivered. It also means being allowed to cancel an order, return a product, get a refund, or repurchase an alternative product where defects in what gets delivered. Efficiency in this process and responsiveness in handling any complaints form good experience for customers. All these aspects, independently or mutually complementing and supplementing each other or wholesomely working together, amount to a good experience.

${ }^{26} \mathrm{~A}$ bad experience is contrary to a good experience. It entails the failure in any one of the aspects set out in a consumer's good experience. The bad experiences include placing an order, high pricing, goods delaying to be delivered. Other concerns include customer care, poor communication, counterfeit or poor-quality product, failure to get a refund upon cancelling order, and failing to resolve a dispute arising from a transaction.

${ }^{27}$ S.1(1) of the SGSSA, 2018.

${ }^{28}$ Eighth Edition, 2004, pg. 1298

${ }^{29}$ S. 36(1) and (2) of the SGSSA, 2018. 
may be is considered. ${ }^{30}$ Where the contract is of a sale of specific goods in another place, then that place shall be the place of delivery. ${ }^{31}$

The majority of the customers who reported having had a good experience using the Jumia Uganda platform reported liking the delivery. Some best practices surrounding the delivery of goods ordered include keeping consistent communication. The communication should clarify how, when, and where the customer will receive the goods. Issues such as the convenience afforded to the customer, the customer care and warm attitude of delivery agents, and timeliness in delivery ranked high for customers. One respondent stated that "...delivery on time, meets deadlines, integral and professional. Everything was delivered safely." Another respondent noted, 'I liked their delivery!'

Customers within or around Kampala city reported getting prompt deliveries, taking one to three days. For upcountry customers, they considered delivery within a week as timely and appreciated it.

Section 26(a) of the SGSSA provides that unless a contrary intention appears, where there is an unconditional contract for the sale of specific goods ${ }^{32}$ in a deliverable state ${ }^{33}$, the property ${ }^{34}$ in the goods passes to the buyer when the contract is made, and it is immaterial whether the time of payment or delivery or both get postponed.

For electronically purchased goods or services, the parties enter the contract of sale electronically. The service provider must provide critical requirements for the contract to be concluded. These requirements must be clear, comprehensible, and unambiguous. ${ }^{35}$ These requirements include different technical steps to follow to conclude the contract electronically. A consumer can only order goods after they have entered a contract of sale. Electronic contracts are thus not made when payment or delivery occurs. An electronic contract gets concluded when and where acceptance of the offer occurs. ${ }^{36}$

$$
\begin{aligned}
& \text { Yes I ordered a phone around 15th April and it was } \\
& \text { delivered the following day at my residence inn mukono } \\
& \text { District. I appreciate their services }
\end{aligned}
$$

I've surely shopped. Immediately after placing your order they give $u$ a phone call or email letting $u$ know the period within which $u$ will get your product. And immediately after the dispatch they still do the same. I'd say my experience is good good with them

An excerpt from one respondent on 20th May 2020

It can be observed from the above responses that those who paid for goods cash on delivery didn't experience any challenges. It's also observed that the goods were promptly delivered, and the delivery services exhibited good customer care in their attitudes.

\footnotetext{
${ }^{30}$ shall be that place.

Section 36(2), ibid

${ }^{31}$ S. 36(3), ibid

${ }^{32}$ Section 1(1) of the SGSSA, Supra, defines 'special goods' to mean 'goods and percentage of goods of goods identified and agreed upon by the parties at the time a contract of sale is made and includes undivided shares in specific goods held in common.'

${ }^{33}$ Section 1(4) of the SGSSA, ibid, provides that "goods are in a 'deliverable state' within the meaning of this Act when they are in such a state that the buyer would, under the contract, be bound to take delivery of them."

${ }^{34}$ Means general property in goods and not merely a special property (see s.1(1) of the SGSSA, 2018)

${ }^{35}$ Regulation.12(1) of the Electronic Transactions Regulations, 2013 provides for the following: following - (a) the different technical steps to follow to conclude the contract; (b) whether the concluded contract will be filed by the service provider and whether it will be accessible; (c) the technical means for identifying and correcting input errors prior to the placing of the order; and (d) the languages offered for the conclusion of the contract, among others.
}

${ }^{36}$ Section $14(2)$ of the ETA. 
Meanwhile, those who had a bad experience complained of various aspects in the delivery process. These include the following: -

\section{Delay in deliveries:}

Most of the respondents acknowledged that they had a contractual arrangement for goods to be delivered within an agreed time. The respondents acknowledged having been contacted by sales officials through telephone contacts provided to give details of the deliveries. The delays reported were thus breaches of agreed timelines. One respondent noted that delivery agents take forever to arrive, so the order gets dropped by clients. One respondent noted that 'they never met timelines.'

Section $27(1)^{37}$ sets out thirty days as the performance timeline for an order made for goods or services by electronic means unless otherwise agreed to by parties.

Service providers must provide information about the time within which the goods will be dispatched or delivered. ${ }^{38}$ The consumer may cancel the order after giving written notice of seven days where a supplier fails to execute the order within thirty days or the agreed period. ${ }^{39}$

Section 36(4) of the SGSSA covers the situations experienced by customers during the lockdown time, where most of the contracts bound the seller to send the goods to the buyer. It provides that where no time for sending the goods is fixed, the seller is bound to dispatch them within a reasonable time. ${ }^{40}$ Unless delivery occurs at a reasonable hour, it may be treated as ineffectual. What amounts to a reasonable hour is a question of fact. ${ }^{41}$

This is very relevant because of the risk tied to the passing of property with goods when the sale occurs. The goods remain at the seller's risk until property in the goods passes to the buyer. ${ }^{42}$ Where the property in the goods passes to the buyer at the point of contracting electronically, buyers must efficiently and effectively take that risk fully. Whether delivery has occurred or not, the goods are at the buyer's risk when property in the goods passes on to the buyer. ${ }^{43}$

Where any of the parties cause any delay in the delivery of the goods that leads to loss or damage, the party at fault will bear the risk. ${ }^{44} \mathrm{~A}$ party in control of the goods is liable for any loss or damage caused by the breach and bears the costs except if such cost is covered by his or her insurance policy. ${ }^{45}$

\section{Part delivery of products:}

A respondent had issues with part of his orders being delivered: "I purchased phone jacket and speakers, but I only received the phone jacket." This respondent had specifically opted to pick up the goods from an agent's outlet but found only one of the goods purchased available for pick-up. The respondent abandoned the choice of pursuing the other product. This reduced their confidence in e-commerce services.

Section $24(3)^{46}$ considers failure to comply with provisions protecting consumers as a breach entitling the consumer to cancel the transaction within fourteen days from the date of receiving the goods or services under the transaction. The choice to cancel is optional. ${ }^{47}$ Where such cancelation occurs, the consumer is required to return

\footnotetext{
${ }^{37}$ Ibid.

${ }^{38}$ Section 24(1)(1) of the ETA

${ }^{39}$ Section 27(2), ibid.

${ }^{40}$ Section 36(4), SGSSA, 2018

${ }^{41}$ Section 36(6), ibid.

${ }^{42}$ Section 27(1), ibid.

${ }^{43}$ Section 27(2), ibid.

${ }^{44}$ Section 27(4), ibid.

${ }^{45}$ Section 27(6), ibid.

${ }^{46}$ ETA

${ }^{47}$ Ibid.
} 
the goods and is entitled to a refund of all payments made subject to deductions of direct costs in returning the goods. $^{48}$

Payment on delivery:

Some respondents decried the option to pay on delivery being removed from the platform as another setback. Some customers decided not to place orders when they realized that pay on delivery was not an option or was not available.

I failed because the option to pay on dervery is no longer there.
The option to pay on delivery is removed so I didn't transact.

An excerpt from one respondent on 20th May 2020

Service providers are obliged to provide the manner of payment on their relevant platforms. ${ }^{49}$ Service providers must give various convenient options to consumers to attract a variety of customers to their platforms. It is important to note that a service provider should use a payment system that is secure according to accepted technological standards at the time of the transaction. ${ }^{50}$

Orders made from abroad:

With orders made from abroad for different items from different sellers, a customer noted that they kept receiving emails on shipment in bits, and yet, they could only receive goods after 10 days from the order. This purchase from abroad meant some goods would arrive separately over different timelines. This situation meant that goods would be delivered late, or even perhaps in part as discussed herein above.

Change of delivery location:

Much as the change of location for delivery would be understood due to the movement restrictions during the lockdown, the service provider needed to find ways to keep their customers satisfied by finding convenient locations to deliver goods given the customers were required to stay at home and delivery services were allowed. A respondent noted, before the lockdown, deliveries could be made to different locations but during the lockdown, 'they asked me to change the location for delivering my order during the lockdown, I gave up with them.'

Where there is no contract, express or implied, as to the place of delivery, the place of delivery is the seller's place of business, if the seller has one, and if not, the seller's resident. ${ }^{51}$ In the context of a lockdown, contractual arrangements to change the location of delivery were reasonable, given buyers couldn't move. Restricting such flexibility was thus detrimental to e-commerce.

\section{Failed deliveries:}

Failure to deliver orders to customers was also observed as constituting bad experiences. These failed deliveries ranged from not getting feedback on orders to total failure to deliver confirmed orders. A respondent reported that 'it took three weeks to get feedback on why my order wasn't delivered.' Another respondent stated that their delivery was postponed 3 times, with no reason given for postponing. That Jumia Uganda apologized and rescheduled delivery. However, these experiences led to the loss of confidence in the e-commerce services of Jumia Uganda.

Under section $27(2)^{52}$, failure to execute the order within thirty days or the agreed period entitles the consumer to exercise the option to cancel the order after giving written notice of seven days. Where the supplier fails to supply

\footnotetext{
${ }^{48}$ S.24(4), ibid.

${ }^{49}$ S.24(1)(j), ibid.

${ }^{50}$ S.25(5), ibid.

${ }^{51}$ Section 36(2), SGSSA, 2018

${ }^{52}$ ETA
} 
the orders on grounds of lack of availability of the goods ordered, the supplier is to notify the consumer before the expiry of the agreed time and refund any payment made in respect of the goods within thirty days. ${ }^{53}$

A buyer may maintain an action against the seller or supplier for damages for non-delivery of goods or failure to supply services. ${ }^{54}$

\section{Nature of Transportation:}

The manner of transportation of some products exposed them to possibilities of damage during transit. A respondent raised a concern that an electronic gadget was placed improperly in the delivery van and other products were packed on it which could have damaged it during transportation.

When a seller is required or authorized to send goods to the buyer, delivery of the goods to a carrier for purposes of transmission to a buyer is prima facie taken to be delivered to the buyer. ${ }^{55}$ The seller shall make a reasonable contract with the carrier on behalf of the buyer, having regard to the nature of the goods and other circumstances of the case. ${ }^{56}$ Where such contract is omitted and the goods are lost or damaged in the course of transit, the buyer may decline to treat the delivery to the carrier as a delivery to him or herself or they may hold the seller responsible for damages. ${ }^{57}$

There is a mandatory obligation to have the goods insured where the goods are sent by a route involving sea transit, in which case, the seller must notify the buyer of this, or the risk during transit is borne by the seller. ${ }^{58}$

However, the provision doesn't provide for mandatory insurance where the goods are transported by road. Important considerations should be taken concerning the transportation of delicate goods to protect consumers' rights.

It arrived a clay before it was supposed to reach. My only concern was manner of transportation. It was a fridge, they delivered it in a van. so it was horizontal instead of vertical and they had piled other items on top of the fridge including a $50 \mathrm{~kg}$ bag of rice.

An excerpt from one respondent on 20th May 2020

Section 27(1). ${ }^{59}$ provides that unless otherwise agreed, the goods remain at the seller's risk until the property in the goods is transferred to the buyer. Where the property has been transferred, the goods are at the buyer's risk whether delivery has been made or not. ${ }^{60}$ Where delivery has been delayed through the fault of the buyer or the seller, the goods are at the risk of the party at fault as regards any loss or damage, which might not have occurred, but for the fault. ${ }^{61}$

The sector players need to address the risks involved with delivery of goods by for instance requiring an insurance policy for transportation of delicate products even by road, rail or air. This has a net effect of increasing the cost

\footnotetext{
${ }^{53}$ Section 27(3), ibid.

${ }^{54}$ Section 62(1), Supra note 45.

${ }^{55}$ Section 40(1), SGSSA, 2018.

${ }^{56}$ Section 40(2), ibid.

${ }^{57}$ Section 40(3), ibid.

${ }^{58}$ Section 40(4), (5), ibid.

${ }^{59}$ The SGSSA, 2018

${ }^{60}$ Section 27(2), ibid.

${ }^{61}$ Section 27(4), ibid
} 
of doing e-commerce. An amendment, providing for mandatory insurance policy when transporting delicate products by rail, road or even air can be considered.

\section{Delivery agents:}

Some customers experienced being tossed back and forth by delivery agents of Jumia Uganda in upcountry places or towns when customers are picking up their products. A respondent noted, 'Jumia had issues with one agent Global Link' so they had to move from one agent to another in search of their product. Clarity as to which agent is the delivery agent for a particular product at a given time is very important in boosting customer confidence. Where e-commerce service providers have technical or other contractual challenges with particular delivery agents, they ought to promptly and effectively communicate the same to the customers.

\section{Pricing:}

Reasonable pricing: It was observed that the costs of goods online were reasonable but the cost of shipping or delivery was prohibitive. A respondent noted that 'Prices were fair on purchase but the delivery fee compensated the fair cost.' Some respondents reported doubling of shipment fee for several items. This led to canceling of many orders. A respondent noted 'Items cost low but you are shocked by shipment cost, Price tag multiplied by two. Price for shipping same as the price of the product.' Below is a picture shared by a respondent showing price differences where a product is priced at Shs. 15,500 ends up being purchased at SHS. 236,755 due to shipping costs and customs fees.

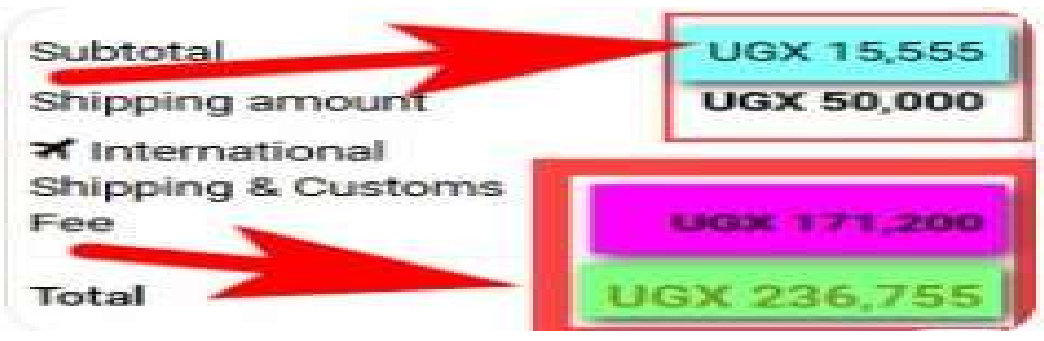

A screenshot shared by a respondent on price variations.

The price in a contract of sale of goods or supply of services may be fixed by the contract, or may be left to be determined in a manner agreed by the contract, or may be determined during the course of dealing between the parties. In such circumstances, the buyer shall pay a reasonable price. A reasonable price is a question of fact dependent on the circumstances of each case and may include a consideration of the prevailing market price. ${ }^{62}$

A service provider is obliged to provide the full price of the goods and services, including transport costs, taxes, and any other fees or costs. ${ }^{63}$ Where the price for the supply of goods or services is dependent on fluctuations in the financial markets that the seller cannot control, such goods cannot be subject to an electronic transaction. ${ }^{64}$

Some respondents reported being confused at the point of making their orders largely due to not understanding how shipping fee equals or at times is more than the cost of the item purchased. Customers were also confused by how goods that could be found and delivered within Uganda are instead found outside the country. This was treated with suspicion and it led to orders being canceled.

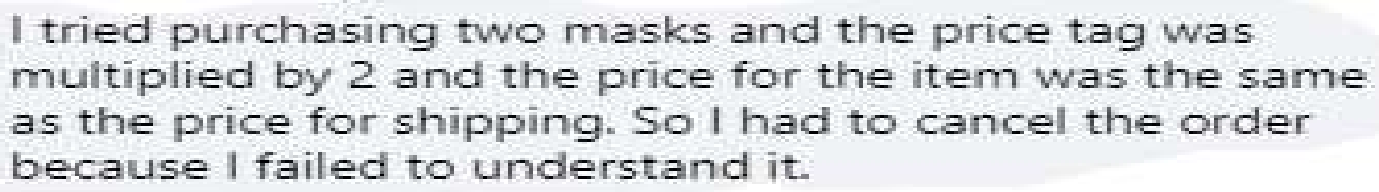

An excerpt from one respondent on 20th May 2020

\footnotetext{
${ }^{62}$ Section 9, SGSSA, 2018.

${ }^{63}$ Section 24(1)(i), ETA.

${ }^{64}$ Section 24(7)(e), ibid.
} 
Communication:

Good communication, contacting the customer, keeping them informed of timelines, and meeting the timelines in delivery were high notes for those who reported having had a great experience shopping on Jumia Uganda. One respondent stated, "When an order is made, they do contact you up to the time of delivery." Another respondent also observed, 'Upon placing an order, they call or email to give you the period of delivery of the product, experience is good.'

Meanwhile, bad communication highly contributed to the bad experiences of Jumia Uganda during the period under research. A respondent observed regarding claiming a refund, "You call no one picks and if they pick, they tell me stories. 'Poor communication left a feeling of betrayal and being taken advantage of among the respondents, with most in this category resolving not to use the platform again.

Section 2 of the Electronic Transactions Act ${ }^{65}$ defines a service provider to among others mean 'any public or private entity that provides to the users of its service the ability to communicate using a computer system.' Effective communication must not be just facilitated but practiced by e-commerce platforms to guarantee the required confidence.

\section{Products description:}

Most of the respondents who had good experiences reported receiving the products they ordered for. One of the respondents stated that "the product I expected was the exact one." Whilst that is a positive attribute, some negative aspects were evident in the responses of many respondents. These include among others the following:

Poor quality and counterfeit products: To counterfeit is to "unlawfully forge, copy, or imitate an item, especially money or a negotiable instrument or other officially issued items of value or to possess such an item without authorization and with the intent to deceive or defraud by presenting the item as genuine." ${ }^{66}$ Counterfeiting includes producing or selling an item that displays a reproduction of a genuine trademark, usually to deceive buyers into thinking they are purchasing genuine merchandise. ${ }^{67} 64 \%$ of the respondents were concerned about the poor quality of products they purchased over the Jumia Uganda platform. One respondent noted, 'I ordered clothes and electronics but got disappointed with their flash discs which are 'kumbe' Chinese made'. Another respondent shared of a 'product delivered not functioning, it was fake!' Further, another respondent observed 'Product paid for didn't match what was delivered, a cheaper and fake one was delivered; product worked 2 days and crushed.'

Not fitting description: Some of the respondents also reported receiving products that didn't fit the description of what they ordered. A respondent reported, 'poor quality, they deliver completely different items.' Another respondent stated that "the size of the product was not the same as what they delivered."

Whereas some of the respondents rejected the goods and asked for a refund of their money, others accepted the goods and paid for them nonetheless.

A seller or service provider is under an obligation to describe the main characteristics of the goods which are sufficient to enable a consumer to make an informed decision on the proposed electronic transaction. ${ }^{68}$ In a contract for the sale of goods by description, there is an implied condition that the goods shall correspond with the description. ${ }^{69}$

There is a further implied condition that goods under a contract are reasonably fit for that purpose where goods are sold by description which it is in the course of the seller's business to supply. ${ }^{70}$ Goods are of satisfactory quality if they meet the standards that a reasonable person would regard as satisfactory, taking into account any description of the goods, the price, and all other relevant circumstances. ${ }^{71}$

\footnotetext{
652011

${ }^{66}$ Black's Law Dictionary (8th ed. 2004)

${ }^{67}$ Black's Law Dictionary (8th ed. 2004)

${ }^{68}$ Section 24(1)(h), ETA

${ }^{69}$ Section 14(1), SGSSA, 2018

${ }^{70}$ Section 15(2)(a), ibid.

${ }^{71}$ Section 15(5), ibid.
} 
Where goods are delivered to the buyer, which he or she has not previously examined, the buyer shall not be taken to have accepted them until he or she has had a reasonable opportunity to examine them to ascertain whether they conform with the contract. The seller is therefore bound, on request, to afford the buyer a reasonable opportunity to examine the goods to ascertain whether they conform with the contract. ${ }^{72}$

Where the seller delivers to the buyer a quality or description of goods less than the seller contracted to sell, the buyer may reject them, but where the buyer accepts the goods so delivered, the buyer shall pay for the goods at the contract rate. ${ }^{73}$

Overall, getting the wrong product or poor quality or counterfeit (fake) products discouraged most of the respondents from purchasing on e-commerce platforms. The customers who bought counterfeit products didn't get any remedies. E-commerce platforms need to find ways to guarantee better quality products. Agents who trade on the platform must be held liable for the proliferation of counterfeit products.
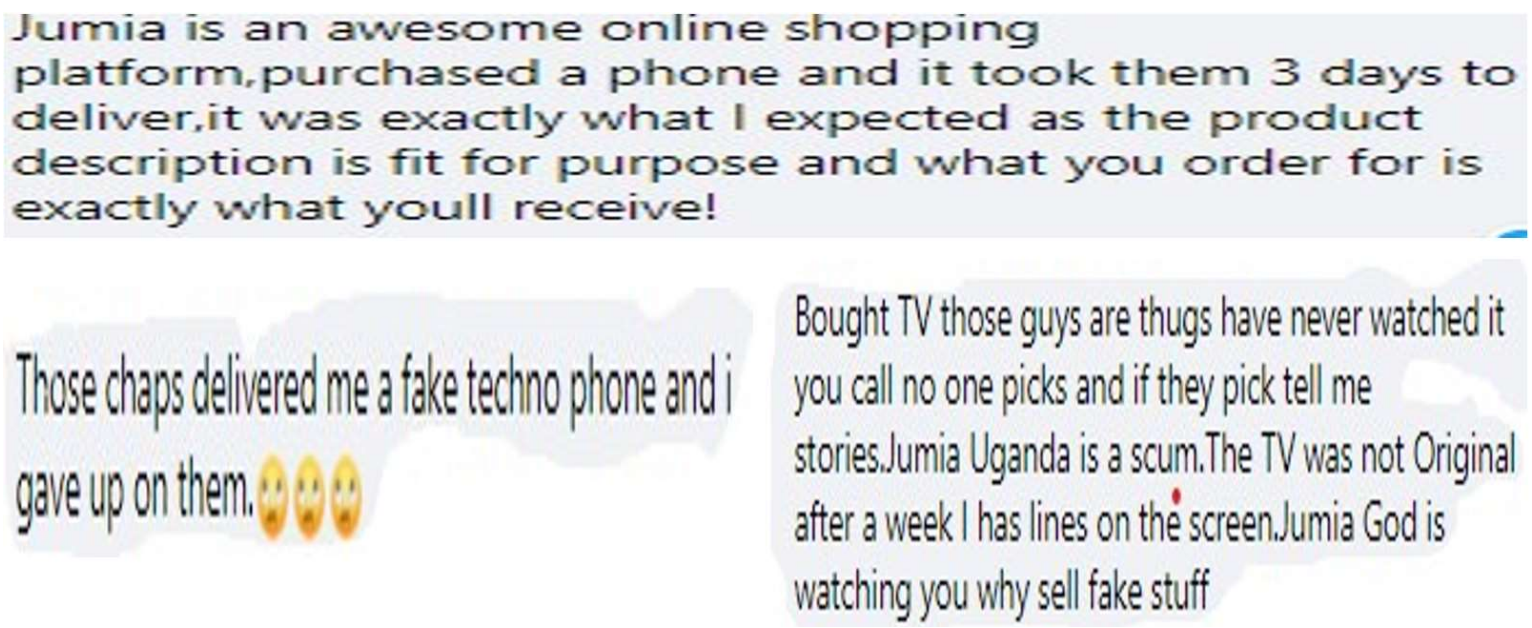

Excerpts from some respondents on $20^{\text {th }}$ May 2020

As in the above excerpts, some respondents' expectations about the products they ordered were met but there were others who were bitterly disappointed. The quality of products sold in the market needs to regulated by the regulatory and standards body. E-commerce platforms owe it to their consumers but also to the industry to monitor the quality of goods sold on their platforms.

\section{Cancellation, Return, and Refund:}

The question of cancellation and refund is critical for e-commerce to thrive. Section 24(1) (n) of the ETA requires a person offering goods or services online to provide on their platform the return, exchange, and refund policy of the person. Section 24(2) provides that a person offering goods and services shall provide a consumer with the opportunity to review the entire electronic transaction; correct any mistakes; and withdraw from the transaction before placing an order.

Several respondents reported having been refunded their money upon the cancellation of their orders. One stated, 'I cancelled the order the same day Friday and by Monday I was refunded'. Another respondent observed "After making several calls I was told that it is out of stock; I got refunded. I took 2 days to get the refund.". Such respondents seemed to trust the platform and be more willing to transact on the platform again.

However, there were also a number who experienced the contrary. A respondent observed, "I made calls and calls and gave up and abandoned the money. " Another respondent noted he had been demanding UGX 450,000/- since February 2020 for a canceled order of which the product was returned and he was promised money in 3 days. He

\footnotetext{
72 Section 42(1), (2), ibid

${ }^{73}$ Section 37(3), ibid.
} 
proposed to buy another product worth a similar amount but the proposal was objected to. Yet another respondent stated he has been 'demanding Jumia 116000 shillings since November 2019'.

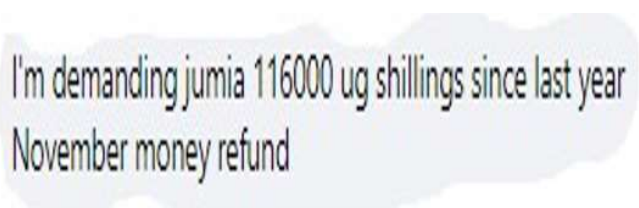

Those guys are not dependable. They deliver vromg item and when you decide to get back your momey they start playing games; I here order something else, was there am item called "something else" when l was ordering? I tried "something else" it was fake. I tried getting my momey. they said buy "something else". I made calls and calls, I gave up and even abandoned the money. They are fake, fake and fake. Till they prove themselves by refundind my money, but it is almost zyears now

Excerpts from some respondents on $20^{\text {th }}$ May 2020

According to the law, a consumer may cancel a transaction before or after receiving the goods when conditions set out in the law are not complied with. ${ }^{74}$ Upon cancelation, the consumer shall return the goods to the person who offered them or cease using the service, and the person selling the goods or offering the service shall refund all payments made by the consumer subject to deduction of direct costs of returning the goods. ${ }^{75}$

The right to cancel a transaction, even without giving a reason, is absolute and unfettered except for financial costs that may have necessarily been expended. Drawing from the various respondents, the cancellation and refund policy are a key consumer confidence booster in e-commerce. Respondents who failed to receive their amounts of money indicated having a loss of confidence not just in the service provider but the whole e-commerce industry. Upon cancellation, customers should be given options to purchase alternative goods if they so wish. Policies should not be rigid where there is a willingness to resolve any concerns.

\section{Ordering Products}

It was observed that where customers had different options available to them in making orders, they were more confident and willing to order products online. Where the system was rigid or has limited options, customers were more ready to desist from making orders. A respondent who was told to make a payment of 36,000 before using their service of Jumia Food App opted not to make an order. While another respondent who was asked to 'change the location for my order in respect to delivery' opted to abandon making an order.

\section{The option to pay on delivery is removed so I didn't transact. \\ I failed because the option to pay on delivery is no longer there.}

Excerpts from some respondents on $20^{\text {th }}$ May 2020

Customers who wish to make orders but have a choice of payment methods should be given the liberty to do so. The removal of the option to pay cash on delivery discouraged customers who would have made orders.

\footnotetext{
74 Section 24(3), 25(1) ETA

${ }^{75}$ Section 24(4), 25(2), (3) ibid.
} 
Platforms should be more flexible in giving customers options on how to make orders and when and how to pay for particular products.

\section{Complaint handling/Dispute Resolution}

Respondents used phone calls and emails to raise any challenges they faced during the transaction. There were successful cases of complaints being addressed leading to an apology, the rescheduling of deliveries, and even the refund of the money to customers. However, options to purchase alternative products were objected to, leaving the customer without remedy. It is also noted that a number of the respondents lodged the complaints through the sales or store agents, delivery agents and direct calls to Jumia Uganda call attendants.

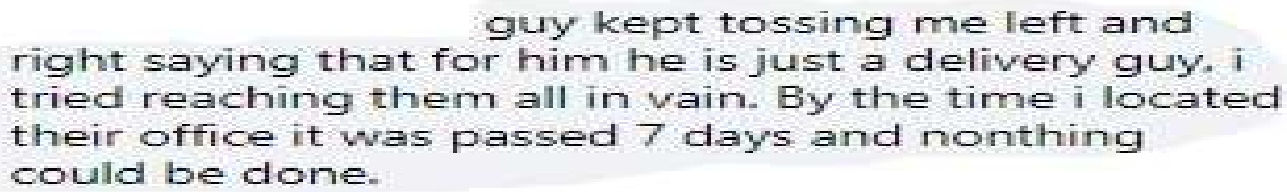

An excerpt from a respondent on $20^{\text {th }}$ May 2020

Mediatory approaches and negotiations through telephone calls were largely used to resolve any disputes. The nature of the response by Jumia Uganda staff, or officials and agents involved in the transaction, had a determinative outcome of the disputes.

Where the response was positive, the dispute was mostly resolved through a refund or rescheduled delivery. Where the response was negative or insolent, the customers tended to abandon their claims and had an attitude of a generalized dislike or disgust for the platform in particular and e-commerce in general.

Regulation 18 of the Electronic Transactions Regulations 2013 encourages a person to report service providers who do not provide the information required for consumer protection to the authority ${ }^{76}$. The authority shall inquire into the report and take necessary action.

The regulations do not provide clarity as to the procedure adopted in handling any complaints raised. It leaves the action of inquiry at the discretion of the authority. This lacuna in the law can give rise to abuse or arbitrariness. The Constitution of Uganda guarantees the citizens' right to just and fair treatment in administrative decisions. ${ }^{77}$

Section 32(2) of ETA and Regulation 19 of the Electronic Transactions Regulations provide procedure and form in which any complaints may be made. A supplier or seller who fails to supply the information required commits an offence and is liable on conviction to a fine not exceeding six currency points. ${ }^{78}$

A close examination of the provision on unlawful activities shows it is restricted to compliance with the provisions of section 24 of the Act. The regulations however, do not preclude a person or consumer from agreeing to different terms in a contract or applying to court for relief to prevent or stop infringement of any right. ${ }^{79}$

As it is, the legal and regulatory framework does not provide clear institutional support for protection of consumer rights. The sanction for non-compliance with consumer protection requirements is weak and not deterrent in nature. There is room for other administrative actions to prevent or stop infringement of any rights of the consumers. However, there is no specificity with regard to which entity may exercise such administrative power. ${ }^{80}$

Such provisions leave the consumers unprotected and at risk of possible abuse by sellers or service providers. None of the respondents shared information on their knowledge about the legal process for raising complaints under the law. The respondents seemed unaware of the procedural or institutional framework available to resolve

\footnotetext{
${ }^{76}$ In regulation 2 of the Electronic Transactions Regulations, 'authority' means the National Information Technology Authority established by the National Information Technology Authority, Uganda Act, 2009.

${ }^{77}$ Article 42 of the Constitution of the Republic of Uganda, 1995 as amended.

${ }^{78}$ Regulation 20, Electronic Transactions Regulations, 2013.

${ }^{79}$ Regulation 17(1)(a) and (b).

${ }^{80}$ Regulation 17(2).
} 
such disputes. The court system, though available, is risky and time consuming with regard to the nature of the breaches and values involved.

What is apparent is that some customers have lost good sums of money where the disputes have not been resolved amicably. Such consumers opt to give up on their monies or following up on the issues.

\section{Other concerns}

Network connectivity: One concern that emerged from the respondents is the recurrent infrastructural challenge of network connectivity. Whereas it was observed that internet data service providers reduced the cost of data and removed charges on mobile money services, some respondents reported experiencing network failures. One respondent observed, 'When the network was down and could not pay, they (sales officials) called me back a few days later..., they helped me .... twice.'

Network connectivity remains an infrastructural challenge across the country which calls for sector players to advocate for further investment in infrastructure development and reduced costs.

Not offering change: another key observation from some respondents was that most delivery agents don't carry change. This caused payment challenges for customers who didn't have small notes during a lockdown situation. It meant that they would be forced to move around looking for change or else pay a little more than required owing to lack of change.

The presentation of the issue suggested a deliberate practice by the delivery agents rather than sheer coincidence. Payments electronically should perhaps be considered in ways that don't require a customer to pay any extra charges. The delivery agents should be encouraged to carry change in the course of making deliveries for instances of cash payments.

\section{Conclusion and Recommendations}

E-commerce experiences need to be improved for all consumers of the e-services. The more stakeholders have a good experience, the more attractive the platform will become, especially in uncertain times presented by Covid19.

More categories of goods could still be purchased online because of the perceived eagerness from the side of consumers to access more genuine and quality products at fairly affordable and reasonable costs. Service providers need to diversify their product lines and even services they can offer in the e-markets so as to grow their businesses.

For a successful e-commerce platform, close attention must be paid to the delivery processes. Consumer confidence is highly tagged to the turn-around time between making an order and receiving the goods ordered.

Delivery agents and e-commerce platforms must have properly structured contracts that guarantee consumer satisfaction. Delivery agents are the face of the e-commerce platforms. The platforms must invest in training to improve on their customer care skills.

Where a particular product can be sourced from within the country, and thus be sourced affordably, the platforms should facilitate such trade. Platforms should be designed to allow consumers to make choices of whether to purchase from within the country or abroad.

Market players must pay close attention to inculcate values that uphold a sense and demand for quality of goods. E-commerce platforms must play a central role in guaranteeing the quality of products they sell to consumers by entering contractual arrangements that bind sellers of the goods to specific quality approved by the platforms. Proper validation and certification process of goods sold on the platform would go a long way to address the counterfeit challenge. A self-regulated and member driven association can play a critical role in tailoring such initiative.

Implementing a more flexible cancellation, return and refund or repurchase policy would guarantee a receptive environment for e-commerce.

The lack of a clear dispute handling process that is cost-effective needs careful consideration. Persons who have lost money in the process of purchasing products or services on an e-commerce platform need mechanisms for the refund of their money. An alternative online dispute settlement mechanism should be urgently explored. 


\section{References}

1. OECD Expert Group on Defining and Measuring E-Commerce, April 2000, see https://stats.oecd.org/glossary/detail.asp?ID=758;

2. T. Garín-Muñoz, T. Pérez-Amaral, Factores determinantes del comercio electrónico en España. Boletín económico de ICE, Informacion Comercial Espanola, 3016 (2011), pp. 51-65

3. Kevin Taylor-Sakyi, Big Data: Understanding Big Data, Engineering and Applied Science, Aston University, Birmingham, England, 2016, Available at: (PDF) Big Data: Understanding Big Data (researchgate.net)

4. E-commerce Market Size, Share \& Trends Analysis Report by Model Type (B2B, B2C), By Region (North America, Europe, APAC, Latin America, Middle East \& Africa), And Segment Forecasts, 20202027, Published May 2020, See: E-commerce Market Share, Growth \& Trends Report, 2020-2027 (grandviewresearch.com)

5. Fernando Fernández-Bonilla, Covadonga Gijón, Bárbara De la Vega, E-commerce in Spain: Determining factors and the importance of the e-trust, Telecommunications Policy, 2021, 102280, ISSN 0308-5961, https://doi.org/10.1016/j.telpol.2021.102280. (https://www.sciencedirect.com/science/article/pii/S0308596121001841),

6. UNCTAD, Ugandan e-commerce platforms power recovery from COVID-19 crisis, 28 July 2020, also

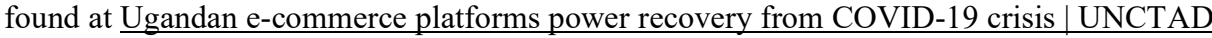

7. Mesut Savrul, Cüneyt Kılıç, E-Commerce as an Alternative Strategy in Recovery from The Recession, $7^{\text {th }}$ International Strategic Management Conference, Elsevier Ltd, Procedia Social and Behavioral Sciences, Vol.24, 2011,pg. 247-259 doi: 10.1016/j.sbspro.2011.09.055

8. Tomoya Kawasaki, Hisayuki Wakashima, Ryuichi Shibasaki, The use of e-commerce and the COVID19 outbreak: A panel data analysis in Japan, Transport Policy, Volume 115, 2022, Pages 88-100, ISSN 0967-070X,https://doi.org/10.1016/j.tranpol.2021.10.023. (https://www.sciencedirect.com/science/article/pii/S0967070X2100305X), [Accessed on $28^{\text {th }}$ October 2021]

9. A. Bhatti, H. Akram, H.M. Basit, A.U. Khan, S. Mahwish, R. Naqvi, et al. E-commerce trends during COVID-19 Pandemic, International Journal of Future Generation Communication and Networking, 13 (2) (2020), pp. 1449-1452, ISSN: 2233-7857 IJFGCN,

\section{Acknowledgment:}

First thanks to God for life and to my family for the love and support that enabled me write this paper especially in between two lock-downs caused by COVID-19. I also thank the various friends on Facebook whose willingness and responses to the research question formed the relevant data analysed in this paper. Special thanks to Prof. Anthony C. Kakooza and Mr. Nelson Abiti for your insights and invaluable wisdom that has given birth to this publication. 